\title{
Oficina do ócio: um convite para o sujeito
}

\author{
Sonia Alberti \\ Adriana Cajado Costa \\ Jacqueline de Oliveira Moreira
}

O presente artigo apresenta uma reflexão teórica sobre o lugar das oficinas terapêuticas no campo da saúde mental. Acreditamos que os novos espaços oferecidos à loucura na sociedade contemporânea possibilitam a produção de novos dispositivos clínicos. Assim, problematizamos a ideia laboral subjacente às oficinas terapêuticas para apresentar a ideia de uma oficina do ócio, que convoca o sujeito ao seu espaço de liberdade.

Palavras-chave: Loucura, psicanálise, sujeito, oficina terapêutica 


\section{A imediaticidade é a realidade, a linguagem é a idealidade, a consciência é a contradição. No momento em que enuncio a realidade, surge a contradição, pois o que eu digo é a idealidade.}

Kierkegaard

O movimento das instituições de saúde mental de ruptura como o modelo asilar revela um novo posicionamento ético, político e clínico frente ao sofrimento do sujeito. O conceito de ética é derivado do termo ethos e este, por sua vez, se refere ao encontro de dois vocábulos gregos: ethos (com eta inicial) e ethos (com épsilon inicial) (Vaz, 2000). Assim, o vocábulo ethos possui duas acepções: a primeira se vincula à ideia de morada do homem e, portanto, de produção de costumes; a segunda se refere a hábito, ou àquilo que se repete no costume. A mediação entre essas duas dimensões ocorre na práxis. Para os gregos, o ethos é coextensivo à cultura e, diferentemente do animal, que é determinado, o homem cria a sua morada. Os novos hábitos (ethos), ao serem criados, interferem nos costumes (ethos). Tal interferência altera a práxis, ou seja, a ação, os atos. E, para modificar os costumes, a morada exige, por sua vez, novos hábitos que, consequentemente, devem mudar a práxis. Pensamos que no momento em que vislumbramos uma outra morada cultural para a loucura, podemos trabalhar novos hábitos que deverão interferir na nossa práxis cotidiana em relação ao portador de sofrimento psíquico. No entanto, é preciso ressaltar que essa nova morada estará sempre em construção, atualizando continuamente as práticas. Atualmente, a proposta de uma 
"nova morada" de acolhida da loucura visa o desasilamento, convocando, necessariamente, a um reposicionamento na práxis.

Birman (1989) anuncia que assistimos, na história do Ocidente, a duas posições em relação à loucura: a trágica e a crítica. A posição trágica aparece na pré-modernidade, em que não existe um espaço destacado para a figura antropológica do louco. Por isso mesmo, ele é incluído no seio da sociedade, não sem que com isso seu destino seja trágico - entendido aqui como sem saída, de forma inamovível.

A posição crítica, ao contrário, sugere a possibilidade de uma mobilidade da posição subjetiva do louco, o que, ao mesmo tempo, leva a sua exclusão da cena social. Tal posição aparece com o início da Era da Razão, na modernidade. Cria-se a ideia de que é possível mudar o louco e, para isso, seria necessário primeiro isolá-lo.

A proposta freudiana anuncia a possibilidade de uma revisitação de ambas as posições, levantando a hipótese de que, ao mesmo tempo em que se pode respeitar totalmente a singularidade de cada sujeito, a partir do laço social criado pela psicanálise, e assim manter o sujeito incluído no seio da sociedade, é possível dialetizar sua posição de forma que a fenomenologia que apresenta não seja inamovível. Com isso, Freud pesquisa e expõe novas posições e intervenções frente ao sofrimento psíquico, instaurando uma nova discursividade (Foucault, 1969). Entretanto, os processos históricos são morosos. Se ao longo do século $\mathrm{XX}$ os efeitos do trabalho de Freud, que dava fala e voz ao sujeito, certamente se multiplicaram, a luta antimanicomial só começou a ter voz no Brasil a partir de 1970.

A instalação de dispositivos clínicos de acolhida do sofrimento mental apresenta-se como um processo dinâmico e contínuo. No fim da década de 1980, muitos hospitais ainda se encontravam presos ao modelo disciplinar (Foucault, 1975) de intervenção. Alguns profissionais mais sensíveis à necessidade de dar voz ao sujeito tentaram, de maneira ensaísta, algumas modalidades de intervenção. Citamos o caso de uma psiquiatra que, frente ao incômodo do ócio paralisante dos internos do hospital em que trabalhava, decidiu investir em dois projetos: primeiro, ela solicitou à direção do hospital a compra de instrumentos musicais para trabalhar com os internos a construção de uma banda. Projeto interessante, que revelava uma intenção de investimento, mas se assentava em seu desejo neurótico, rapidamente contrariado pelo modo como responderam os sujeitos psicóticos associados em torno de sua banda. A psicose pressupõe uma relação diferente com o tempo e com o ritmo, que podem não favorecer, necessariamente, a harmonia musical. No caso citado, ocorreu que cada interno se apossou de um dos instrumentos e se pôs a tocá-lo de acordo com seu ritmo pessoal, inviabilizando o desejo neurótico de construção de uma banda. Frustrada nessa 
primeira tentativa, a psiquiatra solicitou, em um segundo momento, a compra de tintas para que os internos pintassem os muros do hospital psiquiátrico. Nesse caso, o desejo neurótico veio da direção do hospital, que esperava uma pintura linear, que fizesse conjunto. A psiquiatra, já mais atenta às diferenças nos modos de subjetivação, desejava que os pacientes inscrevessem suas subjetividades nesses muros. Essa história, quase anedótica, revela o processo titubeante da construção de novos dispositivos clínicos de acolhida do sujeito portador de sofrimento psíquico. Há, na realidade, um grande debate em curso sobre as propostas de intervenção que, se estão cada vez mais maduras, com oficinas terapêuticas que representam um grande campo de crescimento dos dispositivos clínicos, ao mesmo tempo também são debitárias da morosidade dos processos históricos.

\section{A oficina: sua história}

O termo oficina tem sua origem no latim medieval: opifficina que, sincopado, se tornou officina. Segundo o Etymological Dictionary of Latin, a palavra deriva de opifficium, tendo dado origem também a ofício. Mas o prefixo latino $o p$, que desapareceu com a síncope, é na realidade a tradução do grego ante e, portanto também, anti, de forma que "nos compostos, significa no caminho de, contra, e expressa impedimento e oposição" (Valpy, 1828, verbete $O p$ ). Diante de tal observação, não se pode deixar de relacionar um pequeno texto de Sigmund Freud (1910), no qual ele aponta que, não raras vezes, uma palavra originalmente expressava ao mesmo tempo dois sentidos antitéticos. De todo modo, na Idade Média a palavra opifficina referia-se ao exercício de um ofício, a um lugar onde se faz consertos, ou a dependências de igrejas e conventos, como cozinha, refeitório ou despensa. Lugar laborativo para tecer, consertar ou construir, o que decidiu de sua acepção como local de trabalho, mesmo se, originalmente, também poderia ser entendida como antitrabalho.

No que se refere à especificidade das oficinas terapêuticas, Galletti (2004) faz uma revisão do estado da arte e aponta os estudos de alguns autores como Leal (1999 apud Galletti, 2004) e Rocha (1997, apud Galletti, 2004) para mapear os usos e funções do que se nomeia com o termo oficina no campo terapêutico nos dias atuais. Para Leal (1999 apud Galletti, 2004), três espaços eram reconhecidos na função de oficina: o de criação, o de atividades manuais ou mecânicas e o de convivência. Já em Rocha (1997, apud Galletti, 2004) há uma divisão a partir do que é produzido pelo grupo: 1. Produção de objetos para o mercado; 2. Produção de objetos artísticos para comercialização; 3. Enfoque na 
relação do oficineiro com o objeto utilizado na oficina sem incluir o objetivo da comercialização ou gosto do mercado, o que se diferencia das duas anteriores. Os significantes trabalho e mercado giram em torno dos objetivos de reinserção social e socialização, tentando adequar o sujeito à norma capitalista. É por essa combinação entre trabalho, tratamento e reconhecimento no mercado que Galletti (2004) alerta que "as práticas com as oficinas, portanto, devem estar sempre atentas ao seu parentesco com o trabalho, no sentido capitalista, buscando criar condições para que essa relação possa permitir experimentações menos atreladas aos imperativos reificantes da produtividade econômica" (p. 35). Acrescentamos que nunca é demais lembrar o lema que se lê ao se entrar no que foi o campo de concentração nazista em Auschwitz: "O trabalho liberta", orientação para uma produção massiva e cuja finalidade, que aqui retemos, era a do absoluto aniquilamento do sujeito.

Os significantes adequação, reabilitação e reinserção social, tão presentes nos textos das Leis em Saúde Mental, veiculam também uma Weltanschauung própria ao estágio atual do capitalismo na chamada alta, hiper ou pós-modernidade. Em troca de uma reabilitação, de uma inclusão social pelo trabalho segundo Correa (2008), essa é uma estratégia usada desde o surgimento dos asilos, no século XVIII -, por intermédio do que pode ser produzido para alcançar o valor monetário, não poucas vezes se responde com amor e reconhecimento em muitas oficinas terapêuticas. Assim, as oficinas terapêuticas são produto também de uma história e de uma cultura, e sofrem as ações de profissionais que em seus atos veiculam uma concepção de mundo e de homem.

Algumas oficinas estabelecem uma meta a cumprir, centram os trabalhos em um único tipo de produto escolhido a priori, e avaliam seu sucesso conforme o reconhecimento do mercado, a partir da aceitação de seu produto como mercadoria a ser consumida. Os discursos de sua eficácia e socialização - presentes nas falas quando o sucesso do produto é atingido - promovem um "inclusionismo" politicamente correto, por ser asséptico e estar em conformidade com a demanda do mercado, de acordo com o capitalismo contemporâneo. Nele, cada vez mais se fazem equivalências, o que pode levar ao apagamento das diferenças, ao disfarce cada vez maior das abjeções que não são sem consequências para uma exclusão ainda maior. Como observa Glyn Daly (2006),

... há um perigo de que a política de equivalência seja tão distorcida que se transforme num modo de disfarçar a situação dos que estão verdadeiramente na abjeção ... Com isso, os abjetos podem ser duplamente vitimados: primeiro, por uma ordem capitalista global que os exclui ativamente, e, segundo, por um "inclusionismo" asséptico e politicamente correto que os torna invisíveis dentro de sua floresta pós-moderna, de sua tirania das diferenças. (p. 23)

Rev. Latinoam. Psicopat. Fund., São Paulo, v. 14, n. 3, p. 499-512, setembro 2011 
$\mathrm{Na}$ fase atual do capitalismo, o signo trabalho ganhou maior força, e atrelou os processos simbólicos de pertencimento à inserção social, ao reconhecimento do trabalho realizado pelo indivíduo. Incluir os doentes e deficientes no mercado de trabalho virou certificação de sua socialização e inclusão social, e nas oficinas eles aprenderiam um ofício. Esse "inclusionismo asséptico", no diálogo com a indústria farmacêutica, produziu medicações valiosas e também excessos próprios à medicalização e patologização. Fato que Lacan (1971-1972) muito bem pontuou quando disse que o hospital psiquiátrico é o "lugar onde o discurso capitalista é perfeitamente coerente consigo mesmo" (p. 55, aula de 6/1/1972).

Sabemos que a inclusão do objeto não é a inclusão do sujeito. Vale aqui um exemplo de um usuário de Centro de Atenção Psicossocial (CAPS) que pintava belíssimas mandalas, ou as fazia com jornal e depois as tecia com tantas cores e formas que ficavam grandes e belas. Cada vez que suas mandalas eram vendidas, ele sucumbia a uma crise. Ele não entendia como podia reduzir toda aquela mandala a algumas cédulas de dinheiro com as quais ele não tinha a menor relação. O que ele almejava era ver nos olhos do outro o reconhecimento de sua obra, mas não as queria no campo mercadológico. O valor de troca para ele desqualificava sua obra.

Finalmente, herdeiras de um ideário que remonta à antipsiquiatria (Galletti, 2004, p. 32), originalmente as oficinas terapêuticas - então normalmente chamadas de T.O. (terapia ocupacional) - veicularam a crença da cura pela arte ou pelos trabalhos manuais como mediadores na socialização e reinserção social. Podemos nos perguntar: Em que as propostas de oficinas que aparecem no interior da luta antimanicomial se diferenciam das propostas de oficinas ocupacionais e artísticas presentes nas instituições asilares? Guerra (2008) propõe organizar as práticas das oficinas ao longo da história das instituições psiquiátricas em quatro formas discursivas. A primeira modalidade é definida como o discurso do déficit. Nesse caso, a oficina aparece como uma forma de entreter, mas infantiliza o sujeito e oferece uma ocupação para preencher o ócio. Já o discurso da estética representa outra forma de pensar as oficinas. Percebemos nesse discurso uma preocupação psicológica, porque a arte é pensada como uma forma de expressão para o louco. A terceira modalidade se refere ao discurso da cidadania, em estreita consonância com os ideais da reforma psiquiátrica, que defende a livre circulação das pessoas com transtornos mentais pelos serviços, comunidade e cidade, abrindo, pois, o espaço para buscar o cuidado em vez da cura. Por fim, essa terceira modalidade abriu espaço para que, mais recentemente, surgisse um discurso que introduz um corte nos três anteriores: é o discurso do inconsciente, que visa a contemplar a singularidade do louco, e trabalha com a possibilidade de simbolização da história de cada um, independente de qualquer visada de uma reinserção social que pode não ser escolhida pelo sujeito. 
Em consequência, apesar de ser necessário reconhecer que o discurso da cidadania promoveu oficinas em que se visa contemplar a singularidade do louco com o aporte da psicanálise, anuncia-se, em alguns contextos, uma situação de conflito, pois de um lado temos as exigências do discurso hoje politicamente correto das oficinas como um espaço de articulação da cidadania e, de outro, temos o desejo do sujeito de fazer ou não laço com as oficinas. A luta pela reinserção na cidade pode produzir um excesso de enquadramento que não permite o surgimento do sujeito. Já não é esse, hoje, o contexto mais divulgado das oficinas terapêuticas. No entanto, ele ainda é bastante presente e, para exemplificarmos uma outra orientação que essas oficinas podem ter, trazemos a público uma experiência que se estruturou na contramão do que aqui criticamos. Para introduzi-la, retomemos rapidamente a noção de ócio.

\section{Otium cum dignitate}

O processo de industrialização instaurou a modernidade, e trouxe para o operário uma jornada de trabalho que ultrapassava quatorze horas diárias. Vários estudiosos, então, tentaram compreender a lógica capitalista do trabalho, sua ética e sua moral. Em seus elogios ao ócio, eles formulam uma crítica ao excesso de trabalho e à negatividade em relação ao ócio e ao lazer. Busca-se o lado positivo da preguiça e de sua aliança com o ócio inteligente, que resultaria de uma resistência ao imperativo: trabalhe!

Genro de Marx, Lafargue (1883) defende a ideia de que se deve combater o amor ao trabalho, uma "paixão moribunda", fruto da aliança do poder econômico com a moral religiosa, como também observava Weber (1905). Lafargue (1883) escreve:

A moral capitalista [...] fulmina com o anátema o corpo trabalhador; toma como ideal reduzir o produtor ao mínimo mais restrito de necessidades, suprimir as suas alegrias e as suas paixões e condená-lo ao papel de máquina entregando-o ao trabalho sem tréguas nem piedade.

Russell (1932) critica a ordem na qual cresceu, "ouvindo que o ócio é o pai de todos os vícios", que situava o trabalho no campo da virtude. O autor defende a diminuição das horas diárias de trabalho, almejando o tempo para o lazer, para o ócio, no sentido de preservar um tempo destinado ao prazer pois, ao contrário da barbárie, a civilização é uma conquista da classe ociosa, que "cultivou as artes e descobriu as ciências; escreveu os livros, inventou as filosofias, e refinou as relações sociais".

Rev. Latinoam. Psicopat. Fund., São Paulo, v. 14, n. 3, p. 499-512, setembro 2011 
“A divina preguiça”, crônica publicada por Mário de Andrade em 1918, trata de uma preguiça digna, uma preguiça responsável pelas mais profundas construções simbólicas. Ele escreve: "A arte nasceu porventura de um bocejo sublime, assim como o sentimento do belo deve ter surgido duma contemplação da natureza". O ócio que dá dignidade é, assim, uma experiência simbólica, como a liberdade, e normalmente o encontramos, de fato, nos verbetes sobre liberdade, quando estudamos os dicionários de filosofia. Senão vejamos: o otium cum dignitate é uma liberdade pessoal. Cada um pode "abandonar por algum tempo seu 'negócio' para dedicar-se ao 'ócio' (isto é, ao 'estudo'), para desse modo melhor cultivar sua personalidade" (Mora, 2001, p. 1735).

$\mathrm{Na}$ Antiguidade, o trabalho manual era tarefa do escravo. Os homens da polis, os cidadãos, dedicavam-se à política, à filosofia, às artes e à contemplação, ao otium cum dignitate, entendido como ascese (Lacan, 1971), ao passo que o escravo preguiçoso era torturado no tripalium - instrumento de tortura formado por três paus -, pois não tinha direito ao ócio. Daí o termo neg-ócio, que negativiza o ócio, rebaixando-o ao estatuto da preguiça no contexto da escravidão.

Em 15 de janeiro de 1969, Lacan contrapõe o otium cum dignitate da Antiguidade ao otium cum indignitate dos tempos atuais, justamente porque nestes o imperativo do trabalho domina:

Vocês têm direito a férias para comprar um bilhete na estação de Lyon. Primeiro é preciso pagar por ele, depois vocês vão correndo para os esportes de inverno, onde, durante quinze dias, vocês se empenharão numa trabalheira danada, que consiste em fazer fila ao pé dos teleféricos. O camarada que não vai trabalhar nas férias, é indigno. O otium, por ora, é cum indignitate. Em outras palavras, a recusa do trabalho, em nossos dias, depende de um desafio, coloca-se e só se pode colocar como um desafio. (p. 109)

\section{Oficina do ócio}

Denominamos aqui de Oficina do ócio a experiência singular de uma psicóloga e artista plástica de orientação psicanalítica em sua inserção em um hospital psiquiátrico. O que fazer com pacientes institucionalizados e entregues a perambular pelo hospital, negando-se a participar de atividades laborativas ou recreativas, sem condições de encaminhamento às oficinas do CAPS, num estado de ociosa indignidade? A direção do hospital frisava com frequência a gravidade dos pacientes, justamente por estarem ociosos.

Munida de materiais diversos, aptos para a chamada reciclagem, a psicóloga colocava-se à disposição para construir algo, mas de um novo lugar: o de oferecer

Rev. Latinoam. Psicopat. Fund., São Paulo, v. 14, n. 3, p. 499-512, setembro 2011 
aos pacientes a oportunidade de serem ouvidos. Antes de se dirigir ao espaço destinado pela instituição para o manuseio dos materiais, ela circulava entre os usuários e conversava com eles. Conversas despidas de uma amarração a priori, sem as proteções de uma apresentação formal que, geralmente, sustentam uma demanda normatizadora.

No primeiro momento, uma questão ecoou para os pacientes: o que essa psicóloga quer? As aproximações se deram inicialmente aos poucos, e, após um certo tempo, a demanda por fazer parte dessa oficina era tamanha que o número de participantes teve de ser limitado, sendo preciso mesmo negar pedidos de participação que ultrapassassem esse limite. Ao contrário das outras oficinas, que eram específicas - "oficinas de ...", conforme rezavam as portarias do Ministério da Saúde -, esta era uma oficina sem especificação, mas com uma especificidade: tudo era decidido pelos seus membros. O que seria construído, tecido, fabricado era decidido a posteriori. Constituiu-se, assim, um convite a escolher o que fazer para preservar a dignidade do ócio, do sujeito em sua relação com o saber. Um convite ao sujeito e sua emergência, na tentativa de sair de suas derivas aniquiladoras, nas quais movimentos estereotipados conjugados com alta medicação mergulhavam cada paciente em uma massa amorfa indiferenciada, o que os fazia perder a dignidade e receber o selo de intratáveis.

Haveria dois encontros semanais, com o intuito de fazer algo com um tempo que era vivido à deriva e que, originalmente, empurrava os sujeitos ao vazio. Os primeiros encontros despertaram uma demanda crescente. Cada um escolhia em que se engajar, e surgiu um trabalho coletivo. Se naquele mês haviam tomado a decisão de que fariam peças de bijuteria, cada um se implicava naquilo em que sentia ter mais habilidade. A psicóloga e artista plástica apenas os orientava para o melhor uso dos materiais, de forma a alcançar o que pleiteavam.

Em supervisão demarcamos oito pontos centrais sobre a demanda e o manejo da oficina sem nome:

1. "Você escolhe". As outras oficinas eram demarcadas por uma função específica, por exemplo: na oficina de leitura só havia a leitura de livros escolhidos pela monitora, ou aulas de alfabetização; na oficina de pintura só havia a possibilidade de pintar, não existia a possibilidade de não pintar, ou de costurar o que o outro pintaria. Nesta oficina sem nome era possível participar sem ter de fazer algo com as mãos, ou de trabalhar com o mesmo material ou função. Alguns se aproximavam para ajudar ou para observar. Nesse tempo passado observando, a constatação de que alguns conseguiam fazer suas escolhas e produzir algo belo a seus olhos despertava nos que observavam o desejo de saber.

2. "Você sabe". Cada um se perguntava o que poderia fazer ali. Às vezes é difícil escolher quando se acredita nada saber, mas a cada um foi dada a oportunidade 
de testar, alinhavar e tecer suas intuições: uma cor que lembrava o filho, um laço que lembrava a filha, uma imagem que trazia a dor da perda... E, assim, falas, fitas, tintas, arames, madeiras, curvas, círculos e retas construíam as cenas que ficavam diluídas no silêncio e no vazio de um tempo à deriva. Essa oficina promoveu a marcação do tempo do encontro consigo mesmo e com o outro. Um número crescente de usuários solicitava sua participação na oficina, queria fazer parte dela. O CAPS do estado, vizinho ao hospital, começou a requisitar a psicóloga para suas oficinas.

3. "Preciso falar". A oficina foi crescendo, e o tema dos trabalhos era decidido coletivamente. Cada um se implicava na confecção dos objetos a partir de suas habilidades. No Natal, decidiram confeccionar várias estátuas de Nossa Senhora e de santos com adereços. Uns colavam as fitas, outros pintavam a estátua, outros coloriam ou pintavam algumas imagens no tecido. Muitas lembranças surgiam, e muitas demandas de atendimento individual também, e assim foram marcados os primeiros atendimentos individuais daqueles usuários, até então identificados como intratáveis.

4. Fundo musical. Foi decidido que se escutaria música durante a oficina. Escolheu-se uma trilha sonora a partir do gosto de cada um. Cada música tocava um sujeito, que às vezes chorava, às vezes ria, às vezes falava. A cada mês era percebida uma mudança importante, e a psicóloga começou a ser chamada pela direção e pelos psiquiatras do hospital para debater os casos, opinar sobre a possibilidade de diminuir a medicação, encaminhar para outras especialidades.

5. A escuta. A partir dos atendimentos individuais, muito pôde ser feito. Alguns casos de extremo sofrimento puderam ser escutados, questões ligadas a homicídios, relações sexuais etc.

6. Os aniversariantes do mês. Foi decidido que fariam, uma vez por mês, a comemoração dos aniversários, no horário final da oficina. Isso representou o reconhecimento de um trabalho, das relações, do sofrimento, da vida. Alguns nem sabiam mais a data de seu aniversário.

7. As festas. A partir do trabalho na oficina sem nome, seus membros começaram a participar das festas do hospital, que também conjugava um trabalho com um lar abrigado. Antes, esses pacientes não participavam de nada. Agora, se fantasiavam, organizavam peças, festas para dançar.

8. Os conflitos. Os pacientes também perceberam que o conflito não precisava ser desagregador e nem deveriam, necessariamente, ser tomados como indício de novos surtos. Durante a oficina, havia desentendimentos, pequenas 
desavenças. A psicóloga recolocava as regras que haviam sido decididas para o funcionamento da oficina. Muitas vezes houve a necessidade de uma posição dura e firme, fazendo com que a lei fosse ouvida. A oficina não tinha um fazer específico, mas tinha uma lei que a ordenava. E cada um sabia que atos e palavras tinham consequências.

Essa oficina sem nome, que aqui batizamos de Oficina do ócio, mudou a vida desses sujeitos. Isso aconteceu, sobretudo, porque, de um original otium cum indignitate, cada um pôde, na nova oficina, situar-se cum dignitate, a partir do ocium cum dignitate, ou seja, a partir de sua relação pessoal com o saber. Em verdade, tal relação com o saber não seria possível se não houvesse também as diversas "oficinas de..." - de pintura, de escrita, de bordado etc. Sua especificação inscrevera uma boa quantidade de referências significantes no espaço do hospital. Isso fez funcionar a enigmática falta do complemento no nome da nova oficina, de forma a permitir a cada sujeito tirar proveito de algo que o ócio cum dignitate oferece: a oportunidade de questionar a si mesmo.

\section{Referências}

Alberti, S. (2000). O discurso do capitalista e o mal-estar na cultura. Disponível em: <http://www.scribd.com/doc/19133239/Sonia-Alberti-O-Discurso-Do-Capitalist-A-eo-Mal-Estar-Na-Cultura>. Acesso em: 20 dez. 2010.

. Três sujeitos e o diabo. In: DAvid, S.N. (Org.). O diabo é o sexo. Rio de Janeiro: EdUERJ, 2003. p. 125-150.

Andrade, M. de. A divina preguiça. Gazeta de São Paulo, São Paulo, 3 set. 1918. Arendt, H. A condição humana. Rio de Janeiro: Forense Universitária, 1983.

. A crise da cultura. In: Entre o passado e o futuro. São Paulo: Perspectiva, 1997. p. 249-281.

Birman, J. Freud e a crítica da razão delirante. In: Freud 50 anos depois. Rio de Janeiro: Relume-Dumará, 1989. p. 133-148.

BRASIL. Ministério da Saúde. Legislação em saúde mental 1990-2002. 3. ed. revista e atualizada. Brasília: Ministério da Saúde, 2002.

Correa, D. Oficinas: uma reflexão. In: Figueiredo, A.C.; Costa, C.M. (Orgs.). Oficinas terapêuticas em Saúde Mental: sujeito, produção e cidadania. Rio de Janeiro: Contracapa/IPUB, 2008. p. 155-159.

Daly, G. Arriscar o impossível: conversas com Zizek. São Paulo: Martins, 2006. 
Di MAsi, D. O futuro do trabalho: fadiga e ócio na sociedade pós-industrial. Rio de Janeiro: José Olympio, 2001.

Foucault, M. Qu'est-ce qu'un auteur? Littoral, Paris, n. 9, 1983. Conferência pronunciada na Sociedade Francesa de Filosofia, em 22 de fevereiro de 1969.

_ Surveiller et punir. Paris: Gallimard, 1975.

FREUd, S. (1910). Sobre el sentido antitético de las palabras primitivas. 9. reimp. Buenos Aires: Amorrortu, 2007.

Galletti, M.C. Oficina em saúde mental: instrumento terapêutico ou intercessor clínico? Goiânia: Ed. da UCG, 2004.

Guerra, A.M.C. Oficinas em Saúde Mental: percurso de uma história, fundamentos de uma prática. In: Figueiredo, A.C.; CostA, C.M. (Orgs.). Oficinas terapêuticas em Saúde Mental: sujeito, produção e cidadania. Rio de Janeiro: Contracapa/IPUB, 2008. p. 23-58.

LaCan, J. (1969). O seminário. Livro 16. De um Outro ao outro. Rio de Janeiro: Zahar, 2008. . (1971-1972). O saber do psicanalista. Recife: Centro de Estudos Freudianos, 1997. Circulação interna.

LAFARgue, P. (1883). O direito à preguiça. Disponível em: <http://

www.culturabrasil.pro.br/zip/direitoapreguica.pdf >. Acesso em: 20 dez. 2010.

Mora, J.F. Dicionário de filosofia. tomo III. São Paulo: Loyola, 2001.

Russell, B. (1932). O elogio ao ócio. Disponível em: <http:// antivalor.vilabol.uol.com.br/textos/outros/russel.htm>. Acesso em: 20 dez. 2010.

VALPY, F.E.J. (1828). Etymological Dictionary of the Latin Language. Disponível em: <http://books.google.com.br/>. Acesso em: 20 dez. 2010.

VAz, H.C. de L. Escritos de filosofia II: ética e cultura. São Paulo: Loyola, 2000.

Weber, M. (1905). A ética protestante e o espírito do capitalismo. 7. ed. São Paulo: Livraria Pioneira Editora, 1992.

\section{Resumos}

(Workshop of idleness: an invitation to the subject)

This article presents a theoretical reflection on the role of therapeutic workshops in the field of mental health. We believe that new places offered to mental illness in contemporary society allow for the production of new clinical tools. We thus take a 
critical look at the underlying idea of labor in therapeutic workshops, to present the idea of a workshop of idleness, which calls subjects into a space of freedom.

Key words: Mental illness, psychoanalysis, subject, therapeutic workshop

(L'atelier du loisir: une invitation au sujet)

Cet article présente une réflexion théorique sur le lieu des ateliers thérapeutiques dans le domaine de la santé mentale. Nous croyons que la nouvelle situation de la maladie mentale dans la société contemporaine permet la production de nouveaux dispositifs cliniques. Ainsi, nous proposons un regard critique sur l'idée du travail sousjacente aux ateliers thérapeutiques pour y introduire la notion d'un atelier du loisir qui invite l'individu à connaître son espace de liberté.

Mots clés: Maladie mentale, psychanalyse, sujet, atelier thérapeutique

(El taller del ocio: una invitación al sujeto)

Este artículo presenta una reflexión teórica sobre el lugar de los talleres terapéuticos en el campo de la salud mental. Creemos que los nuevos espacios ofrecidos a la enfermedad mental en la sociedad contemporánea posibilitan la producción de nuevos dispositivos clínicos. Puesto esto, problematizamos la idea laboral subyacente a los talleres terapéuticos para en contraposición presentar la idea de un taller del ocio, que convoca el sujeto a su espacio de libertad.

Palabras clave: Enfermedad mental, psicoanálisis, sujeto, taller terapéutico

Citação/Citation: Albertı, S.; Costa, A.C.; Moreira, J.O. Oficina do ócio: um convite para o sujeito. Revista Latinoamericana de Psicopatologia Fundamental, São Paulo, v. 14, n. 3, p. 499-512, set.2011.

Editor do artigo/Editor: Profa. Dra. Ana Cristina Costa Figueiredo e Profa. Dra. Andréa Máris Campos Guerra

\section{Recebido/Received: 2.3.2011 / 3.2.2011 Aceito/Accepted: 22.6.2011 / 6.22.2011}

Copyright: () 2009 Associação Universitária de Pesquisa em Psicopatologia Fundamental/ University Association for Research in Fundamental Psychopathology. Este é um artigo de livre acesso, que permite uso irrestrito, distribuição e reprodução em qualquer meio, desde que o autor e a fonte sejam citados/This is an open-access article, which permits unrestricted use, distribution, and reproduction in any medium, provided the original author and source are credited.

Rev. Latinoam. Psicopat. Fund., São Paulo, v. 14, n. 3, p. 499-512, setembro 2011 
Financiamento/Funding: As autoras declaram não ter sido financiadas ou apoiadas/The authors have no support or funding to report.

Conflito de interesses/Conflict of interest: As autoras declaram que não há conflito de interesses/The authors declare that has no conflict of interest.

\section{Sonia Alberti}

Professora Adjunta do Instituto de Psicologia da Universidade do Estado do Rio de Janeiro - UERJ (Rio de Janeiro, RJ, Br); Procientista da Universidade do Estado do Rio de Janeiro - UERJ (Rio de Janeiro, RJ, Br) e Pesquisadora do Conselho Nacional de Desenvolvimento Científico e Tecnológico - CNPq (Brasília, DF, Br); Psicanalista; Membro do GT: Dispositivos Clínicos em Saúde Mental.

Rua João Afonso, 60 casa 22

22261-040 Rio de Janeiro, RJ, Br

Fonefax: (21) 2527-3154

e-mail: sonialberti@gmail.com

\section{Adriana Cajado Costa}

Professora convidada do PGCult/UFMA - Programa de Pós-Graduação Cultura e Sociedade da Universidade Federal do Maranhão (São Luís, MA, Br); Vice-Líder do Grupo de Pesquisa Crisol da Universidade Federal do Maranhão - UFMA (São Luís, MA, Br); Psicanalista; Doutoranda do Programa de Pós-Graduação em Psicanálise da Universidade do Estado do Rio de Janeiro - UERJ (Rio de Janeiro, RJ, Br); Discente Participante do GT: Dispositivos Clínicos em Saúde Mental.

Rua das Mitras, Ed. Cap Ferrat, Apto. 402 - Renascença II 65075-770 São Luís, MA, Br

Fone: (98) 3227-8734.

e-mail: adricajado@hotmail.com

\section{Jacqueline de Oliveira Moreira}

Professora Adjunta da Potifícia Universidade Católica de Minas Gerais - PUC Minas (Belo Horizonte, MG, Br); Psicanalista; Membro do GT: Dispositivos Clínicos em Saúde Mental. Rua Congonhas, 161 30330-100 Belo Horizonte, MG, Br

Fone: (31) 3223-3951

e-mail: jackdrawin@yahoo.com.br 